current than before. This has been confirmed by Franck and Pitres, who have further shown that the diminished excitability cannot be accounted for by mere shock or hæmorrhage, inasmuch as the neighbouring grey matter acted as readily as before. They have further given reasons for believing that the contrary results obtained by Richet, ${ }^{38}$ and Bubnoff and Heidenhain ${ }^{39}$ are due to the action on the cortex of the chloral and morphint under which their experiments were performed. These agents, without doubt, paralyse the excitability of the grey matter, It was noted by Fritsch and Hitzig, in their experiments, that the anodal closure was a more effective stimulus than the cathodal-a fact which might be interpreted as signifying that the real stimulus proceeded from the virtual cathode in the deeper layers of the cortex, or termination of the medullary fibres. This, however, has been ebown by Gerber, ${ }^{40}$ not to be uniformly the case. Gerber finds that when the cortex is in a normal state the cathode is the more effective stimulant, but that when changes have occurred from long exposure the anode predominates. These experiments would, therefore, indicate that in the normal condition of the brain the laws of galvanic excitability are the same as for motor nerves.

Another important difference between the reactions of the cortex and the subjacent medullary fibres, which was first pointed out by Franck and Pitres, is that the time lost between the application of the stimulus and the occurrence of muscular contraction is much greater in the case of the former than the latter. This interval, after deducting the time necessary for the transmission of the impulse through the spinal cord and motor nerves, indicates a retardation in the cortex of 0.045 second. After removal of the grey matter and application of the electrodes to the medullary fibres, the period of retardation diminishes to 0.030 second, that is, about one-third less, and this difference is put at a considerably higher figure by Bubnoff and Heidenhain.

The signification of this fact is that the grey matter of the cortex does not behave like an inert layer, which merely allows transmission of the electric current to the medullary fibres, but, like other nerve centres, stores up and transforms the stimuli which it has received into its own energy.

There is also a characteristic difference between the muscular curves registered on stimulation of the cortex and medullary fibres respectively. In the latter case the curve rises abruptly, and is of short duration; while in the former it rises more gradually, is more prolonged, and frequently marked by the occurrence of a secondary tetanus, which latter is altogether peculiar to the cortex, and is never seen when the medullary fibres alone are stimulated. The cortex is apt, after repeated stimulation, or after the receipt of a succession of stimuli, each insufficient to produce reaction, to respond by tonic, followed by clonic, spasms of the correlated muscles of a truly epileptic type. These convulsions tend to spread and become generalised in the order and sequence originally described by Hughlings Jackson. They never occur on stimulation of the medullary fibres alone, apart from the intervention of the grey matter of the cortex on the one side or the other, and cannot be produced if the cortical centres are entirely destroyed on both sides. The duration of the effects of stimulation of the medullary fibres is strictly proportional to that of the stimulus which is applied to them. We shall also see as we proceed that the effects of localised destruction of the cortex are the counterpart of those of irritation, however induced, and we may from this conclude that there is the same functional differentiation in the cortex as in the medullary fibres, even if the facts which I have just mentioned should not be regarded as of themselves completely establishing this proposition.

38. Sur les Circonvolutions Cerebrales, 1879.

39 Pfüger's Archiv. f. Physiologie, 1881.

40 " Beitrïge zur Lehre von der electrischen Reizung des Grosshirns," Pflïger's Archiv für Physiologie, Band 39, 1888.

Whooping-Cough in Paris. - At a recent meeting of the Council of Hygiene of the Department of the Seine, a report was presented by M. Ollivier which showed that 520 children had died of whooping-cough in Paris during 1889. Of these, 13 were aged less than one month, 207 between one month and a year, 142 between one and two years, 142 between two and five, and 16 between five and ten years. The Council passed a resolution that the disease should be looked upon as a very serious illness in children under two years of age, and that cases should be isolated for at least fifteen days after the disappearance of the whoop, or, if possible, till the cough has finally ceased.

\section{A CASE OF GASTROSTOMY.}

\section{By A. W. MAYO ROBSON, F.R.C.S.,}

Honorary Surgeon, Leeds General Infirmary ; Honorary Consulting Surgeon, Batley Hospital ; Lecturer on Practical Surgery, Yorkshire College; and Examiner in the Victoria University.

ALTHOUGH gastrostomy for non-malignant obstruction is a fairly successful operation, when performed for cancer of the œsophagus it is one of extreme fatality. Any means, therefore, which will help to reduce the mortality may be worth recording.

The patient whose case is related below was operated on by a method first suggested by Mr. Greig Smith, and described by him in his work on Abdominal Surgery. After the operation the patient lived in a state of comparative comfort for eleven months, during the whole of which time he never took a particle of food except through the artificial opening into the stomach. By this method of suture the peritoneal coat of the stomach is kept in apposition with the parietal peritoneum in a continuous circle for some distance from the point where the stomach is to be opened. The insertion of two loops of silver wire, as suggested by Mr. Bryant, serves to mark the spot at which the stomach is to be opened, and by means of these wires the stomach can be manipulated whilst the silk suture is being applied. With a round needle threaded with from 12 to 15 inches of moderately thick silk, a continuous suture is passed in the anterior wall of the stomach, in a circle of about 2 inches in diameter under the peritoneal coat, taking up a little of the muscular layer as well, the suture being made to emerge and leave a loop at every three-quarters of an inch of the circle, thus leaving about six loops protruding from the serous surface of the stomach. (Fig. 1).

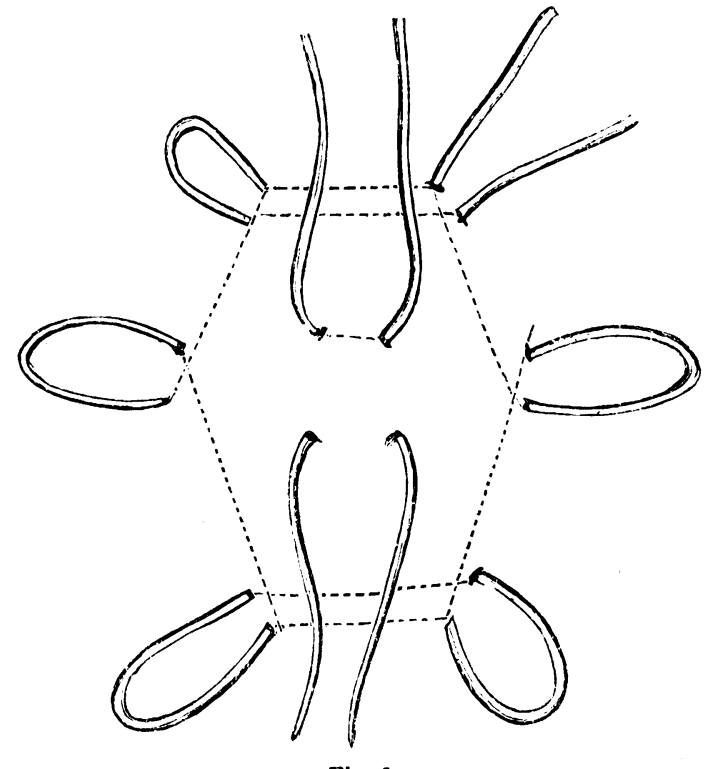

Fig. 1.

At corresponding situations on the skin, about half an inch from the edge of the wound, a handled needle with a hooked eye is pushed through all the layers of the abdominal walls, catches up the loops, and brings them to the surface of the abdomen one after another. As each loop is drawn up a piece of elastic tubing or a piece of catheter is slipped into it. The loops are then moderately tightened over the catheter by pulling at the ends of the silk. Finally, the ends of the silver suture are hooked under the catheter, serving to keep the exposed par s well up in the gaping wound. (Fig. 2). It will thus be seen that by this method of fixing the stomach accurate peritoneal apposition is obtained over a large space, and the stomach is not dragged out too far, thus lessening the risk of a dribbling fistula. Moreover, the method is rapidly and easily carried out.

History of the Case. ${ }^{1}-\mathrm{T}$. O., aged 51, admitted to the Leeds In- 
firmary April 18th, 1889, under Dr. Churton's care, and transferred to Mr. Mayo Robson for surgical treatment May 29th. The patient had been married twenty years. No history of any venereal disease, or of swallowing any hot or caustic fluid. Five months before admission he began to have difficulty in taking solid food, which frequently regurgitated, and was at times returned by vomiting. This lasted for several weeks, when he was somewhat better for a short time; the vomiting, however, returned, and regularly persisted after every meal. For some little time before admission liquids as well as solids were rejected. He had lost flesh considerably.

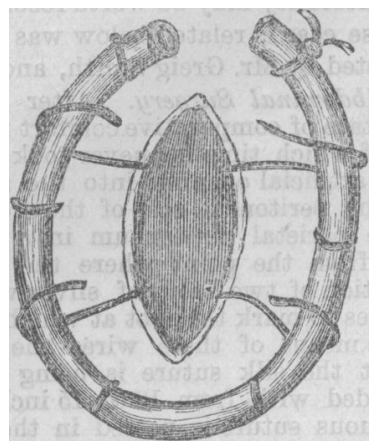

Fig. 2.

On admission the patient was very thin and wasted. $\mathrm{He}$ vomited immediately after taking any kind of food or liquid, but had no pain before, during, or after vomiting. The abdomen was flaccid, and he had no pain in the epigastrium. On attempting to pass œsophageal bougies they were always arrested at a point $12 \frac{1}{2}$ inches from the teeth, and not even the smallest could be passed through the stricture. When transferred to the surgical ward no food had entered the stomach for several days, and he was being fed by nutrient enemata.

Operation May 30th.-The usual antiseptic precautions were adopted, the abdomen having been purified by a carbolic dressing worn during the previous twelve hours. The patient was anasthetised with the A.C.E. mixture. A vertical incision of 3 inches, starting from just below the costal margin, was made along the outer border of the left rectus. After the parietal peritoneum had been incised to the full extent of the wound, it was sutured to the skin margin; the stomach was then fixed to the abdominal wall in the manner described at the beginning of the paper. The wound was dressed with a layer of sal alembroth gauze, over which was placed a large pad of salufer wool.

May 31st. The patient passed a fair night, the nutrient suppositories and enemata having been given every four hours alternately. Temperature normal.

June 1st. No pain or sickness, pulse fair, temperature normal ; enemata continued.

June 2nd. Patient rather weaker, and complaining seriously of thirst, which was relieved by the injection of a pint of tepid water into the bowel.

June 3rd. Enemata not retained; temperature normal ; patient feeling weaker. A small opening was made into the stomach by means of a tenotomy knife. A No. 4 catheter was passed through the opening, and the following fluid introduced into the stomach at 11 A.M. by means of a funnel and india-rubber tubing attached to the end of the catheter: beef-tea, 3 ounces; condensed peptonised milk, 3 drachms; brandy, 3 drachms; water to 6 ounces. 3.30 P.M. Beef-tea, 5 ounces; peptonised milk, 5 drachms; Brand's essence, $\frac{1}{2}$ ounce; brandy, 4 drachms; water to 11 ounces. 9 P.Mr. Beef-tea, 4 ounces; peptonised milk, 5 drachms; yolk of one egg; Brand's essence, $\frac{1}{2}$ ounce; brandy, 1 ounce: water to 12 ounces. 11 P.M. Patient felt very comfortable since being fed.

June 4th. Had a good night, and expressed himself as feeling very well. Fed by the funnel and tube with: milk, 8 ounces; beef-tea, 5 ounces; Brand's essence, 1 ounce; yolk of one egg; brandy, 4 drachms, at 9.15 A.M. Milk, 8 ounces; brandy, $\frac{1}{2}$ ounce; beef-tea, 4 ounces; yolk of one egg, at 1.30 P.M. Brandy, $\frac{1}{2}$ ounce; milk, 6 ounces; beef-tea, $5 \frac{1}{2}$ ounces, at 5.30 P.M. Milk, 8 ounces ; brandy, $\frac{1}{2}$ ounce; yolk of one egg; Brand's essence, $\frac{1}{2}$ ounce; beeftea, 3 ounces, at 9.30 P.M.

June 5th. Had a good night, was fed through the tube every four hours with the same kind of food; 12 ounces at 9 A.M.
13 ounces at 1 P.M., 14 ounces at 5 P.M., and 13 ounces at 9 P.M. The patient had improved steadily ever since the stomach had been opened. He usually complained of a sense of fulness just at the time of the fluid being introduced.

June 8th. Sutures removed; slight discharge of gastric juice from stomach, hence a larger catheter was employed.

June 14th. Patient was allowed to sit up, and was fed every four hours through the tube.

June 24th. A short celluloid tube with a stopper was fitted into the wound, and the patient could take it out and reintroduce it for himself, and by taking out the stopper he could easily feed himself through the opening. He was made an out-patient, having gained half a stone in weight, and looking and feeling comfortable.

When seen in August, he had gained over a stone in weight, and seemed very happy and comfortable, which condition continued up to February, 1890, when his general health again began to fail, and he died at his own home from exhaustion, due to the gradual progress of the original malignant disease of the cesophagus on April 11th.

\section{CHRONIC INTESTINAL OBSTRUCTION FOL- IOWING INJURY: LAPAROTOMY.}

\section{BY R. HAMILTON RUSSELL, F.R.C.S.ENG ,} Melbourne, Victoria.

THe following case came under my care on board Messrs. Green and Co.'s ship, Carlisle Castle, during a recent voyage from London to Melbourne.

The patient, A. L., was an ordinary seaman, aged 17 . On October 10th, 1889, while working on the forecastle head in heavy weather, a big sea came over, carried him off his legs, and narrowly missed washing him overboard. In the effort of saving himself he was severely strained and hurt, the right leg seeming to be the part most injured. He tur aed into his bunk, and three or four hours later pain came on in the abdomen and back. This pain became steadily worse, and was of a dull aching character, felt chiefly in the hypogastrium. No vomiting or nausea ; micturition normal.

On October 12th I first saw him, and he gave the above history. He complained of abdominal and lumbar pain; the pain in the leg was gone.

On examining the abdomen, the appearance was quite natural; some tenderness on pressure all over, most marked, however, about the umbilical and hypogastric regions; no distension, no rigidity, no tumour; palpation and percussion revealed nothing abnormal ; face not expressive of marked distress or pain ; tongue clean and moist; pulse remarkably slow, 60 . On standing up he was unable to straighten the trunk completely, but walked in a slightly bent attitude, and the attempt to walk greatly aggravated the pain. He had previously always enjoyed excellent health ; never had typhoid or any other fever, nor had he ever had any abdominal trouble before. Bowels always regular, and had been so up to the date of the accident.

October 13th. Black draught $\zeta_{\mathrm{ij}}$ given in the morning; effect apparently nil; the appetite was fair, but thirst was rather troublesome; urine somewhat scanty and high-coloured; general condition unchanged.

October 14th. Ol. ricini $\xi j$ before breakfast had no effect, but a drop of croton oil given during the afternoon caused a marked aggravation of the pain, and the face began to assume a somewhat distressed look; no action of the bowels took place, however; given one-sixth of a grain of opium every hour; diet, arrowroot and milk in small quantities. Until this day I had not seriously suspected the presence of intestinal obstruction.

October 15th. Fair night; pain much relieved; volunteered that the medicine had caused him to pass more water; told me he had passed small quantities of flatus at times during the last few days. On examining the rectum, well-marked "ballooning" was discovered, the finger seeming to enter a larger cavity; copious enema administered with long tube without effect.

October 19th. Patient had been taking opium and resting in his bunk since last note; the general condition was unchanged; pain and tenderness was diminished; he slept fairly; no nausea or vomiting; facial expression placid, and he lay and read during the day; ho had occasionally passed a little flitus. I thought 